\begin{tabular}{|c|c|}
\hline Title & Expression of thymidine phosphorylase in choroidal malignant melanoma associated with neovascular glaucoma. \\
\hline Author(s) & $\begin{array}{l}\text { Kase, Satoru; Saito, Wataru; Y oshida, Kazuhiko; Namba, Kenichi; Osaki, Mitsuhiko; Ohgami, Kazuhiro; Shiratori, } \\
\text { Kenji; Kitaichi, Nobuy oshi; A dachi, Hironobu; Ito, Hisao; Ohno, Shigeaki }\end{array}$ \\
\hline Citation & $\begin{array}{l}\text { Pathology International, 55(9), 569-573 } \\
\text { https://doi.org/10.1111/.1440-1827.2005.01870.x }\end{array}$ \\
\hline Issue Date & 2005-09 \\
\hline Doc URL & http:/hdl.handle.net/2115/15822 \\
\hline Rights & The definitive version is available at www.blackwell-synergy.com \\
\hline Type & article (author version) \\
\hline File Information & PI55-9.pdf \\
\hline
\end{tabular}

Instructions for use 


\title{
Case Report \\ Expression of thymidine phosphorylase in choroidal malignant melanoma associated with neovascular glaucoma
}

\author{
Satoru Kase, ${ }^{1}$ Wataru Saito, ${ }^{1}$ Kazuhiko Yoshida, ${ }^{1}$ Kenichi Namba, ${ }^{1}$ Mitsuhiko Osaki, ${ }^{2}$ Kazuhiro Ohgami, \\ Kenji Shiratori, ${ }^{1}$ Nobuyoshi Kitaichi, ${ }^{1}$ Hironobu Adachi, ${ }^{2}$ Hisao Ito ${ }^{2}$ and Shigeaki Ohno ${ }^{1}$ \\ ${ }^{1}$ Department of Ophthalmology and Visual Sciences, Hokkaido University Graduate School of Medicine, Sapporo and \\ ${ }^{2}$ Division of Organ Pathology, Department of Microbiology and Pathology, Tottori University, Faculty of Medicine, Yonago, \\ Tottori, Japan
}

\begin{abstract}
Reported herein is a case of 62-year-old man who complained of blurred vision and ocular pain in his right eye. The patient was diagnosed with choroidal melanoma complicated by neovascular glaucoma (NVG) and total retinal detachment, and he underwent enucleation of the eye. The isolated tumor was $2.5 \times 2.5 \mathrm{~cm}$ in size. It was accompanied by intratumoral calcification, and consisted of epithelioid and spindle melanoma cells. There were a variety of microvessels in the stroma of the iris. The expression of thymidine phosphorylase (dThdPase), an angiogenic factor, was examined immunohistochemically. Cytoplasmic immunoreactivity for dThdPase was more prominent in the epithelioid cells than in spindle tumor cells. Another case of choroidal melanoma without NVG had less marked immunoreactivity. These results suggest that the production of dThdPase by melanoma cells correlates with the pathogenesis of NVG.
\end{abstract}

Key words: choroid, dThdPase, glaucoma, histopathology, melanoma

Uveal melanoma is the most common primary intraocular malignant tumor in adults, although its incidence is relatively low in the Japanese compared to Caucasian subjects. ${ }^{1}$ The common initial signs are presence of an intraocular mass, glaucoma, decreased vision, retinal detachment, and cataract. $^{2}$ Although neovascular glaucoma (NVG) is also a welldocumented complication in cases of uveal melanoma, ${ }^{3}$ the mechanism that underlies complication is still controversial.

Thymidine phosphorylase (dThdPase), a type of pyrimidine nucleoside phosphorylase, is essential for DNA synthesis. This enzyme converts 5'-deoxy-5-fluorouridine to

Correspondence: Satoru Kase, MD, PhD, Department of Ophthalmology and Visual Sciences, Hokkaido University Graduate School of Medicine, N15 W7, Kita-ku, Sapporo 060-8638, Japan.

Email: kaseron@med.hokudai.ac.jp

Received 8 January 2005. Accepted for publication 12 April 2005. 5-fluorouracil. It has been reported that dThdPase was identical to platelet-derived endothelial cell growth factor. ${ }^{4}$ Other studies showed that dThdPase and its degradation products have potent angiogenic activities in vivo and in vitro. ${ }^{5,6} \mathrm{We}$ previously demonstrated that expression of dThdPase in malignant solid tumors such as esophageal and gastric carcinomas as well as malignant fibrous histiocytoma was correlated with tumor angiogenesis. ${ }^{7-10}$

In the present report we described the histopathology of a case of uveal malignant melanoma associated with NVG, and present our immunohistochemical findings about the expression of dThdPase in the melanoma cells.

\section{CLINICAL HISTORY}

A 62-year-old Japanese man complained of blurred vision in his right eye, and his primary care physician noted total retinal detachment in the right eye. Despite being advised of the need for surgery, the patient refused any treatment for 8 months before his first visit to Hokkaido University Hospital. Because his symptoms had worsened and ocular pain occurred in the right eye, he was referred to Hokkaido University Hospital on 18 November 2002. Visual acuity was light perception and intraocular pressure was $50 \mathrm{mmHg}$ in the right eye. The left eye was normal. In the right eye, slit-lamp examination showed ciliary injection, corneal epithelial edema and uveal ectropion (Fig. 1a). The anterior chamber was deep and clear. Rubeosis iridis forming peripheral anterior synechiae was also noted. Because the fundus examination showed total retinal detachment, obvious tumor formation could not be confirmed. B-scan echography showed a mushroom-shaped highly echoic lesion, which was thought to have originated from the choroid associated with extensive retinal detachment. Computed tomography (CT) demonstrated an unclear intraocular mass of iso- to low 
density and a small whitish nodule in the mass. The latter mass was suggested to be calcification. Magnetic resonance imaging showed intermediate signal intensity in T1-weighted images, and low intensity in T2. The diagnosis of a uveal malignant melanoma complicated by NVG and total retinal detachment was therefore made. Enucleation of the right eye was performed after informed consent was obtained. Formalin-fixed and paraffin-embedded tissue sections were made from the enucleated sample. No recurrence or metastasis to the left eyeball was observed during 18 months follow up.

\section{IMMUNOHISTOCHEMISTRY}

Paraffin-processed sections of the eye were assessed for dThdPase (antibody against dThdPase was kindly provided by Nippon Roche Research Center, Kamakura, Japan), vascular endothelial growth factor (VEGF), basic fibroblast growth factor (bFGF), and VEGF receptors including fetal liver kinase-1 (Flk-1) and fms-like-tyrosine kinase-4 (Flt-4) ${ }^{11}$ by immunohistochemistry using the streptavidin-biotin immunoalkaline phosphatase complex method. Briefly, sections were de-waxed in xylene, rehydrated through a series of alcohols, and washed in water. All of the sections were heated in $10 \mathrm{mmol} / \mathrm{L}$ citrate buffer $(\mathrm{pH} \mathrm{6.0)}$ in a microwave oven for $15 \mathrm{~min}$ at $94^{\circ} \mathrm{C}$. Following repeated washing in Trisbuffered saline (TBS, pH 7.6) for $10 \mathrm{~min}$, non-specific antibody binding was blocked by $0.1 \%$ bovine serum albumin in TBS for $25 \mathrm{~min}$. The list of primary antibodies used in the present study is given in Table 1. Primary antibodies were incubated at room temperature for $2 \mathrm{~h}$. Slides were washed three times in TBS and the second antibody added. After washing, sections were incubated with a tertiary streptavidin-alkaline phosphatase reagent (DakoCytomation, Glostrup, Denmark). The sections were again washed in TBS and incubated in Vector Red for 15 min according to the manufacturer's instructions (Vector Laboratories, Peterborough, UK), washed, and lightly counterstained with Mayer's hematoxyline for $5 \mathrm{~s}$. We counted at least 1000 melanoma cells in five or more microscopic fields from melanoma tissues. Positive-staining cells were noted by their labeling index as a percentage (\%).

\section{DETERMINATION OF INTRATUMORAL MICROVESSEL DENSITY}

For the determination of intratumoral microvessel density (IMVD), we counted CD34-positive staining microvessels in vessels wholly within the area of the graticule or touching the top or left-hand borders, while vessels touching the bottom or right-hand border were excluded as described previously. ${ }^{12}$ At least five of the most highly vascularized portions within a section were selected and counted under a light microscope at the magnification given by Weidner et al. ${ }^{13}$ Their average numbers were recorded as IMVD.

\section{PATHOLOGICAL FINDINGS}

A soft, blackish, mushroom-shaped mass, measuring $2.5 \times 2.5 \mathrm{~cm}$, was located in the posterior wall of the eyeball (Fig. 1b). Histopathological examination revealed that tumor originated from the choroid, and Bruch's membrane was ruptured. The tumor showed obvious melanin deposition, and irregular-shaped calcification in one part (Fig 1c). There were a variety of microvessels in the stroma of the iris (Fig. 1d). High magnification revealed that the tumor cells consisted of two cell types: (i) epithelioid cells with round to oval nuclei and macronucleoli; and (ii) spindle cells with elongated nuclei and relatively small cytoplasm (Fig. 2a,d, respectively). The tumor was diagnosed as mixed cell type according to the Armed Forces Institute of Pathology (AFIP) classification. ${ }^{14}$ A few macrophages containing melanin were identified in the stroma of the tumor tissue. However, the tumor did not invade the iris, ciliary body, optic nerve, vortex veins, or extraocular tissues.

Next, we focused on dThdPase, one of the angiogenic factors, and analyzed its expression immunohistochemically in order to determine whether some humoral factors are expressed in melanoma cells during the development of NVG. We have already confirmed the specificity of the antibody used in this study by western blot analysis. ${ }^{15}$ The specificity of the immunostaining was confirmed by using TBS instead of the primary antibody for dThdPase (negative control). As a positive control, we examined tumor tissues

Table 1 Primary antibodies used

\begin{tabular}{llll}
\hline Specificity & \multicolumn{1}{c}{ Source } & Clone \\
\hline dThdPase & Nippon Roche, Kamakura, Japan & $654-1$ & Dilution \\
VEGF & Santa Cruz Bioetch, CA, USA & Polyclonal \\
VEGFR (Flk-1) & Santa Cruz Bioetch, CA, USA & A-3 & $1: 1000$ \\
VEGFR (Flt-4) & Santa Cruz Bioetch, California, USA & Polyclonal \\
bFGF & Transduction Laboratories, Lexington, USA & 3 & $1: 200$ \\
\hline
\end{tabular}

bFGF, basic fibroblast growth factor; Flk-1, fetal liver kinase-1; Flt-4, fms-like-tyrosine kinase-4; VEGF, vascular endothelial growth factor; VEGFR, VEGF receptor. 

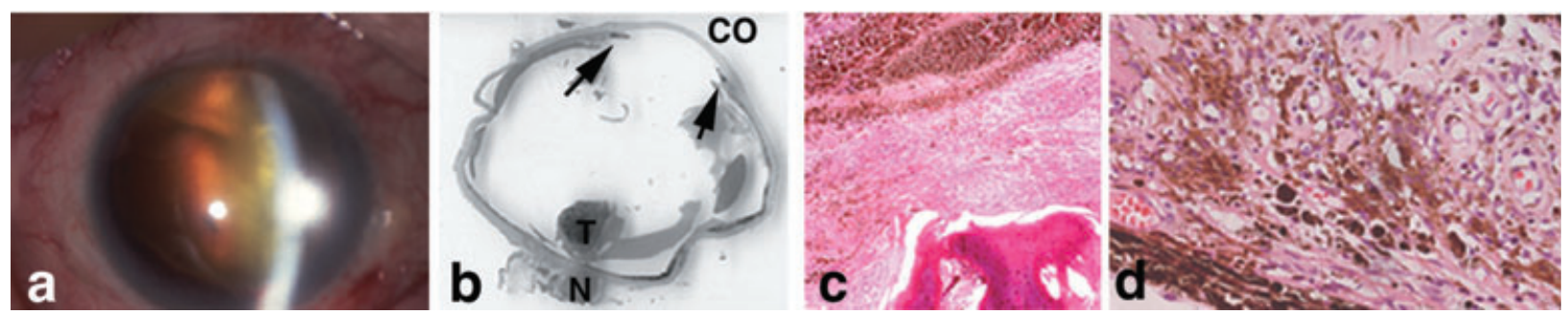

Figure 1 Slit-lamp examination of the right eye on 18 November 2002. (a) Ciliary injection, and corneal epithelial edema as well as uveal ectropion are observed. Extensive retinal detachment can be seen behind the lens. (b-d) Hematoxylin and eosin staining in enucleated sample. (b) In whole eyeball section, tumor is located in posterior uvea (arrow, iris; CO, cornea; T, tumor; N, optic nerve). (c) Histopathological examination shows irregular-shaped calcification in tumor tissue at low magnification. (d) There are prominent microvessels in the stroma of the iris without tumor cell invasion.

Figure 2 (a,d) Histological features and (b,e) immunodetection of thymidine phosphorylase (dThdPase) in choroidal melanoma with neovascular glaucoma (NVG) in the present case. (a) Epithelioid as well as (d) spindle cell-type tumor cells proliferate. The tumor cells have atypical nuclei and scanty cytoplasm with obvious melanin deposition in each cell type. Cytoplasmic and nuclear immunoreactivity for dThdPase is noted in epithelioid tumor cells, the immunoreactivity being (b) more dominant in the cytoplasm than in the nuclei. (e) Several spindle tumor cells express dThdPase. Immunodetection of dThdPase in choroidal melanoma with (c) epithelioid cell- or (f) spindle cell-type tumor cells in the other case of uveal melanoma without NVG. The immunoreactivity in this case (case 4 ) is less marked. Scale bar $=50 \mu \mathrm{m}$.
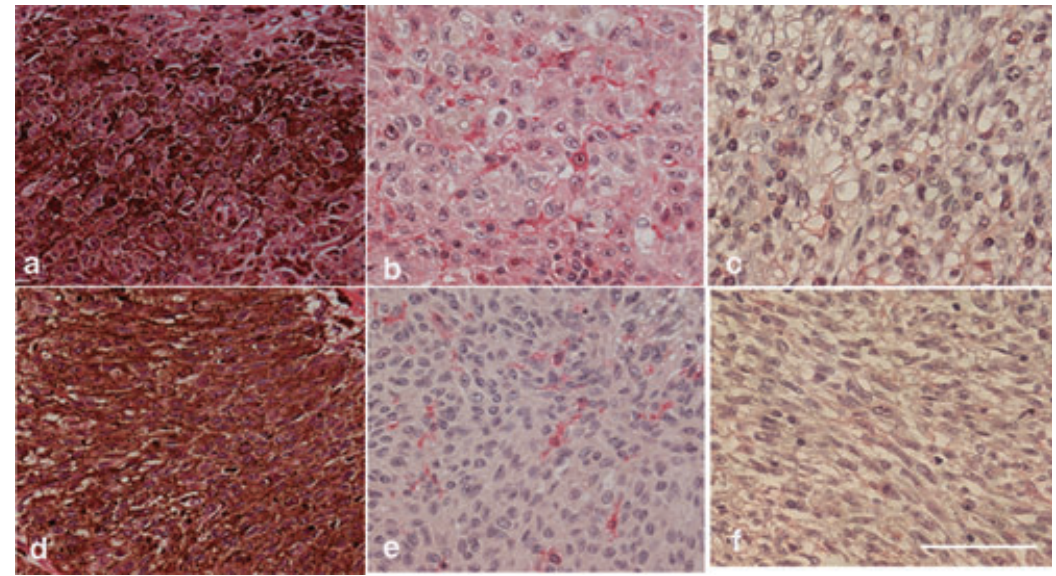

obtained from subjects as reported previously. ${ }^{7-10,15.16}$ The expression of dThdPase in the tissues was evaluated after the melanin was eliminated. Cytoplasmic and nuclear immunoreactivity for $\mathrm{dThdPase}$ was noted in the epithelioid tumor cells, with the immunoreactivity being stronger in the cytoplasm than in the nuclei (Fig. 2b). Several spindle tumor cells were also observed to express dThdPase (Fig. 2e). We also analyzed dThdPase expression using another uveal melanoma specimen that did not have NVG and compared the expression levels between the specimens. We found that the immunoreactivity for dThdPase in the case without NVG was quite low compared with that in the present case with NVG (Fig 2b,c,e,f). In the case without NVG, immunoreactivity for dThdPase was detected in the nuclei and cytoplasm of only a few tumor cells (Fig 2c,f). We did not detect dThdPase expression in any normal ocular tissues except for macrophages infiltrating the tumor tissues. Flk-1 immunoreactivity was detected in almost half of tumor cells in all cases examined. In contrast, only a few tumor cells had cytoplasmic immunoreactivity for VEGF, FIt-4 and bFGF. In the present case with NVG, IMVD was 52. In contrast, the IMVD in melanoma cases without NVG was 42,54 and 94, respectively. These immunohistochemical results are summarized in Table 2.

\section{DISCUSSION}

Enucleation of the eye with uveal melanoma is often required owing to the development of iris neovascularization (NVI) and painful NVG. ${ }^{17-19}$ However, the mechanisms that induce NVI following melanoma have not been clarified. It has been shown recently that angiogenic factors, such as VEGF, produced by parenchymal melanoma tissues are correlated with tumor angiogenesis. ${ }^{20}$ In the present study we focused on another angiogenic factor, dThdPase, and clearly demonstrated its expression in the choroidal malignant melanoma cells immunohistochemically. The dThdPase was expressed much more strongly in the case of malignant melanoma complicated by NVG than that without NVG, suggesting that angiogenic factors produced by tumor cells may play an important role in the pathogenesis of NVG.

In order to examine the correlation between expression of dThdPase in melanoma cells and promotion of tumor angiogenesis, we calculated IMVD in choroidal melanoma cases with and without NVG. In the present study, obvious association between dThdPase expression and IMVD was not observed. Hence, expression of dThdPase might play a more important role in development of NVG than promotion of tumor angiogenesis itself. 


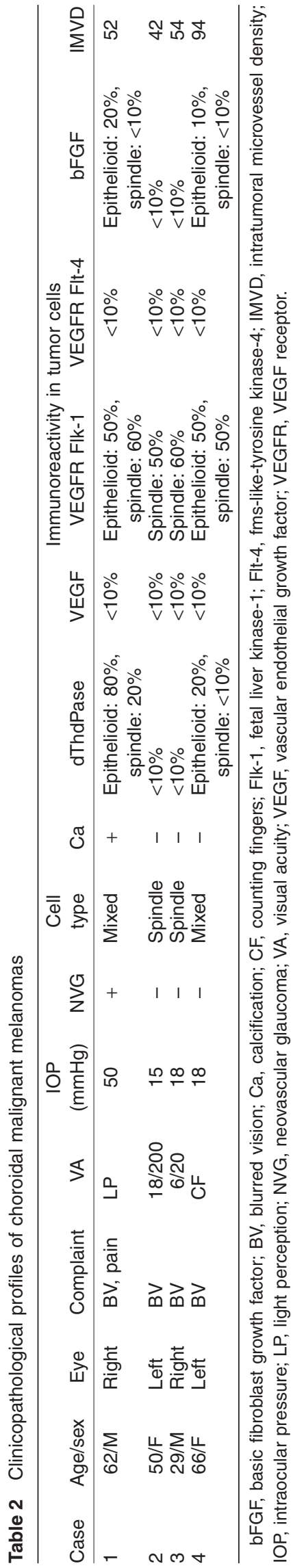

In the present study other angiogenic factors such as VEGF, VEGF receptors and bFGF were also examined in choroidal melanoma tissues. Immunoreactivity of Flk-1, one of the VEGF receptors, was detected in all melanoma cases with or without complication of NVG. It was reported that expression of VEGF receptors on tumor cells correlated with a putative autocrine role of VEGF on tumor cells or stimulation of tumor growth. ${ }^{21}$ We speculated that expression of dThdPase in the present case with NVG played a more pivotal role in development of NVG than that of VEGF receptors.

Histopathologically, more dThdPase expression was detected in epithelioid tumor cells intensely than in spindle cells in the present case. This is in accord with the fact that patients with epithelioid cell-type uveal melanoma generally have poor prognosis compared with patients with spindle cell and mixed cell-type uveal melanoma. ${ }^{22}$ Induction of dThdPase in epithelioid tumor cells might result in the progression of tumor-associated complications.

We have previously demonstrated that dThdPase expression was stronger in the cytoplasm of well-vascularized esophago-gastric carcinoma cells than in the nucleus of such cells. ${ }^{7,8}$ In the present study cytoplasmic and nuclear immunoreactivity of dThdPase was noted in epithelioid melanoma cells, with the former being predominant. The present data were consistent with previous reports ${ }^{7,8}$ and it is suggested that expression of dThdPase in the cytoplasm of melanoma cells plays a critical role in angiogenic activity and neovascularization of the iris.

Irregular-shaped calcification was detected in the melanoma tissue in the present study based on CT and histopathological analysis. Intratumoral calcification in ocular tumors is frequently found in retinoblastoma, but is experienced rarely in uveal melanomas. ${ }^{23}$ Pathological calcification can generally be classified as dystrophic or metastatic. The present patient had no systemic disease affecting calcium metabolism, indicating that the melanoma tissue showed dystrophic calcification. Hypoxia-ischemia might have affected calcium metabolism and caused calcification in the melanoma in the present case, as reported in neural tissues. ${ }^{24}$ The high dThdPase levels in the melanoma in the present case also suggest the presence of ischemia, because it has been shown that dThdPase is induced by ischemia. ${ }^{4}$

In conclusion, dThdPase produced by choroidal melanoma cells is possibly correlated with the pathogenesis of NVG.

\section{ACKNOWLEDGMENTS}

The authors thank Dr Tomoo Ito (Laboratory of Molecular and Cellular Pathology, Hokkaido University School of Medicine, Sapporo, Japan.) for his cooperation in preparation of spec- 
imens. This study was supported by a grant for Research on Sensory and Communicative Disorders from the Ministry of Health, Labor and Welfare, and by Grants-in-Aid for Scientific Research from the Ministry of Education, Culture, Sports, Science, and Technology (MEXT), Japan.

\section{REFERENCES}

1 Sakamoto T, Sakamoto M, Yoshikawa $\mathrm{H}$ et al. Histologic findings and prognosis of uveal malignant melanoma in japanese patients. Am J Ophthalmol 1996; 121: 276-83.

2 Font RL, Spaulding AG, Zimmerman LDM. A clinicopathologic report of 54 cases. Trans Am Acad Ophthalmol Otolaryngol 1968; 72: 877-95.

3 Shields MB, Proia AD. Neovascular glaucoma associated with an iris melanoma. A clinicopathologic report. Arch Ophthalmol 1987; 105: 672-4.

4 Ishikawa F, Miyazono K, Hellman U et al. Identification of angiogenic activity and the cloning and expression of platelet-derived endothelial cell growth factor. Nature 1989; 338: 557-62.

5 Haraguchi M, Miyadera K, Uemura K et al. Angiogenic activity of enzymes. Nature 1994; 368: 198.

6 Miyadera K, Sumizawa T, Haraguchi M et al. Role of thymidine phosphorylase activity in the angiogenic effect of platelet derived endothelial cell growth factor/thymidine phosphorylase. Cancer Res 1995; 55: 1687-90.

7 Kase S, Osaki M, Honjo S, Adachi H, Ito H. Tubular adenoma and intramucosal intestinal-type adenocarcinoma of the stomach: What are the pathobiological differences? Gastric Cancer 2003; 6: 71-79.

8 Okamoto E, Osaki M, Kase S, Adachi H, Kaibara N, Ito H. Thymidine phosphorylase expression causes both the increase of intratumoral microvessels and decrease of apoptosis in human esophageal carcinomas. Pathol Int 2001; 51: 158-64.

9 Yamashita $H$, Osaki M, Ardyanto TD, Yoshida $H$, Ito $H$. Cyclooxygenase-2 in human malignant fibrous histiocytoma: Correlations with intratumoral microvessel density, expression of vascular endothelial growth factor and thymidine phosphorylase. Int J Mol Med 2004; 14: 565-70.

10 Osaki M, Sakatani T, Okamoto E, Goto E, Adachi H, Ito H. Thymidine phosphorylase expression results in a decrease in apoptosis and increase in intratumoral microvessel density in human gastric carcinomas. Virchows Arch 2000; 437: 3136.

11 Shibuya M. Role of VEGF-flt receptor system in normal and tumor angiogenesis. Adv Cancer Res 1995; 67: 281-316.

12 Foss AJ, Alexander RA, Hungerford JL, Harris AL, Cree IA, Lightman S. Reassessment of the PAS patterns in uveal melanoma. Br J Ophthalmol 1997; 81: 240-6; discussion 247-8.

13 Weidner N, Semple JP, Welch WR, Folkman J. Tumor angiogenesis and metastasis: Correlation in invasive breast carcinoma. N Engl J Med 1991; 324: 1-8.

14 McLean IW, Foster WD, Zimmerman LE, Gamel JW. Modifications of Callender's classification of uveal melanoma at the Armed Forces Institute of Pathology. Am J Ophthalmol 1983; 96: 502-9.

15 Shomori K, Sakatani T, Goto A, Matsuura T, Kiyonari H, Ito $\mathrm{H}$. Thymidine phosphorylase expression in human colorectal mucosa, adenoma and carcinoma: Role of p53 expression. Pathol Int 1999; 49: 491-99.

16 Matsuura T, Kuratate I, Teramachi K, Osaki M, Fukuda Y, Ito $\mathrm{H}$. Thymidine phosphorylase expression is associated with both increase of intratumoral microvessels and decrease of apoptosis in human colorectal carcinomas. Cancer Res 1999; 59: 5037-40.

17 Finger PT. Radiation therapy for choroidal melanoma. Surv Ophthalmol 1997; 42: 215-32.

18 Hungerford JL. Management of ocular melanoma. Br Med Bull 1995; 51: 694-716.

19 Shields J, Shields C. Intraocular Tumors. A Text and Atlas. Philadelphia: WB Saunders, 1991.

20 Boyd SR, Tan D, Bunce C et al. Vascular endothelial growth factor is elevated in ocular fluids of eyes harbouring uveal melanoma: Identification of a potential therapeutic window. $\mathrm{Br}$ J Ophthalmol 2002; 86: 448-52.

21 Boocock CA, Charnock-Jones DS, Sharkey AM et al. Expression of vascular endothelial growth factor and its receptors flt and KDR in ovarian carcinoma. J Natl Cancer Inst 1995; 87: 506-16.

22 Seddon JM, Albert DM, Lavin PT, Robinson N. A prognostic factor study of disease-free interval and survival following enucleation for uveal melanoma. Arch Ophthalmol 1983; 101: 1894-99.

23 Shields JA, Shields CL. CME review: Sclerochoroidal calcification: The 2001 Harold Gifford Lecture. Retina 2002; 22: 251-61.

24 Ramonet $\mathrm{D}$, Pugliese M, Rodriguez MJ et al. Calcium precipitation in acute and chronic brain diseases. J Physiol Paris 2002; 96: 307-12. 